\title{
Romero-Fresco, P. (2019). Accessible filmmaking: Integrating translation and accessibility into the filmmaking process. Routledge. 266 pp.
}

Accessible Filmmaking combines three fields of study that are closely related: audiovisual translation (AVT), media accessibility (MA) and filmmaking. While researching present and potential interactions between the three areas is beneficial to all three, this study also throws light on what currently distinguishes them from each other and where the roots of their differences lie. The study and awareness of the complex connections between the three domains is relatively new, even within audiovisual translation studies, and remains a topic of much debate. Accessible Filmmaking provides a welcome contribution to the discussion and is bound to have an impact on both research and practice in all three domains, as it addresses readers who come to Accessible Filmmaking from very different perspectives.

Accessible Filmmaking consists of six chapters. Chapter 1: Introduction. The End of a Long Divorce details how translation was gradually relegated from the post-production stage of the filmmaking process to the films' distribution phase in a bid to cut costs. This led to filmmakers and creative teams losing control over the translation of their films, which in turn had dramatic repercussions on film reception due to the negative impact of poor translations and reduced accessibility. This state of affairs is especially problematic since many filmmakers are not aware of the issues and in global times much of a film's revenue comes from its foreign markets. Moreover, the demand for accessibility is gaining ground, while films themselves are becoming increasingly hybrid and intercultural. According to Pablo Romero-Fresco, the challenge for film today therefore resides in resolving the "maker-expert-user gap", a concept borrowed from Branson (2018), which identifies three problematic areas: firstly, the disconnect between filmmakers and translation/accessibility professionals; secondly, the divide between filmmakers' aspirations and how foreign and sensory-impaired users experience their films; and thirdly, the gap between translation/accessibility professionals and their target users. Accessible Filmmaking makes a case for integrating audiovisual translation and media accessibility into the film production process to the benefit of all. How and why this should be done is detailed in the ensuing chapters.

Chapter 2: Setting the Scene: In Support of a Wide Notion of Accessibility, Translation and Film details the theoretical framework of the book. It enters the debate on the epistemological relations between AVT and MA, proposing a universalist concept of MA (Greco, 2018), which includes wider audiences on the one hand and accessibility to filmic and theatrical production processes as well as content creation on the other. This is supported by research into user needs, film revenues and examples of good practice. One very thought-provoking subsection deals with (some) film directors' and film critics' historical lack of awareness of the effect that translation and accessibility have on users' filmic experiences, an obliviousness shared by many translation professionals. Equally interesting is the discussion of the enlightened attitudes and perspectives of a small group of ethnographic and "cross-cultural" filmmakers, accessible filmmaking (AFM) pioneers whose views have remained outside the scope of AVT to date. Chapter two also introduces the early proponents of universal design in accessibility, while highlighting the limitations of indiscriminately transferring general universal design principles to a media context. A comprehensive update on the current state of AFM in training, 
research and, more particularly, innovative professional practices aims to drive home the feasibility of AFM as a means of creating global films which minimize the difference between their original and translated versions.

Chapter 3: AVT and MA for Filmmakers provides an overview of the major forms of AVT and MA, focusing on how their technical, linguistic, (hidden) ideological and potentially manipulative features can impact specific aspects of the film to which they are "added". The chapter's main aim is to promote communication and understanding between filmmakers and translation professionals. However, this section first and foremost addresses filmmakers. As a result, some of the subsections dealing with the specificities of certain translation or accessibility modes will come across as rather basic to AVT and MA professionals or scholars. Nevertheless, the chapter combines insights from diverse traditional and innovative AVT/MA practices as well interdisciplinary research from outside Translation Studies (TS), such as perception/reception research or studies on multimodal viewing and listening experiences. It also relates the features of specific translation modes to issues of visual aesthetics and filmtechnical concerns with which translation professionals or scholars may be less familiar. In the process, it debunks some generally accepted AVT "knowledge" and guidelines, on the basis of state-of-the-art personal research involving eye-tracking, for instance. The chapter has enormous didactic value for both film and translation students, not least because of the wealth of examples that support the argumentation. It demonstrates convincingly that filmmakers and translation/accessibility professionals share responsibility in the decisionmaking process with respect to the translation modes to be used and the degree of experimentation that might be desirable, resulting, for instance, in the use of integrated subtitles involving creative graphic design and subtitle placement.

Chapter 4: Integrating Translation and Accessibility into the Filmmaking Process discusses the concrete benefit of incorporating professional translation/accessibility in development and pre-production, in production, in post-production, and before distribution (my italics). The wealth of concrete examples is, again, one of the major assets of this chapter. It demonstrates that international productions require the assistance of translators and interpreters from day one, not only for dialogue-writing but also for obtaining subsidies and for on-site communication. However, filmmakers tend to underestimate the importance of professional quality translations as well as the benefits that come from supplying translators and accessibility professionals with pre-production materials. The author's combined knowledge of film studies and translation studies once again lends much weight to his arguments. Moreover, the alternatives on offer are shown to be credible and affordable thanks to the availability of new technologies and text processing know-how. The detailed, often quite technical, examples demonstrate convincingly how integrating the translators into the film crew can eliminate clashes between the original and translated film experience. At present, by contrast, visual design, editing, mise-en-scène and even the narratively motivated use of linguistic variation are often compromised in translated versions. And yet, even when translation is relegated to post-production, team consultation on film editing will anticipate translation/accessibility issues and lead to more satisfactory translation options. Likewise, even collaboration in the pre-distribution phase will yield much better global film viewing experiences than the current divorce between filmmaking and translation could ever produce.

Chapter 5: Integrating AFM into the Film Industry tackles three preconceived ideas related to the feasibility of integrating translation and accessibility into the filmmaking process: the time it would require to achieve it; the impact it may have on current work flows; and the costs 
involved. Obviously, the new type of collaboration proposed and its aim to include user views in the process requires coordination. The author therefore proposes a new professional profile, that of the director of accessibility and translation (DAT), a figure somewhat similar to current film productions' scientific consultants. The new professional would coordinate all translation and accessibility-related issues, possibly with the help of an experienced accessibility user/consultant (a similar profile, that of the accessibility manager (AM) for the scenic arts was already introduced by the European ACT project, see https://pagines.uab.cat/act/ and Remael et al., 2019). An accessibility and translation director would most certainly be useful for large productions. The DAT would produce an "accessibility guide" for the crew, coordinate the access-related work of the entire team and monitor the quality of the translated end product. Pablo Romero-Fresco discusses the functions of the DAT in great detail as well as the desired 16-step workflow for AFM, which sounds more daunting than it actually is. The chapter offers clear schematic work-flow overviews. The author proceeds with details of the costs involved, which need not exceed those of current film AVT/MA. He rounds off the chapter with a discussion of the experiences of directors who have already gone the AFM way, whether inadvertently or consciously, citing interesting production documentation and examples of new creative possibilities.

Chapter 6: Conclusions briefly summarizes the main arguments expounded in the other chapters. The author rightfully claims that " $(\mathrm{t})$ he time is ripe for AFM". The bibliography is extensive and it is followed by a very useful index. However, the conclusions could have included concrete proposals for further research. AFM is still in its infancy and surely all issues have not yet been resolved. Suggestions for further research might have stimulated young scholars and contributed to a conscious expansion of academic interest in AFM, including collaboration between Translation Studies and Film Studies. More research from different perspectives would certainly be welcome. Pablo Romero-Fresco displays extensive knowledge of AVT, MA and film studies, however, his discussion of the limitations and affordances of the different AVT modes is not always balanced. The amount of attention devoted to (integrated) subtitling, for instance, outweighs the attention given to audio description. Moreover, geographically speaking, the focus lies largely on the film accessibility situation in the UK, where the author conducted most of his research.

Nevertheless, Accessible Filmmaking: Integrating Translation and Accessibility into the Filmmaking Process is a great achievement and the author's enthusiasm for the AFM model radiates from his writing style and argumentation. As a reader one is compelled to follow the book's sweeping momentum. The arguments in favour of integrating accessibility into the different stages of the production process are convincing. 


\title{
References
}

Branson, J. (2018, June 4-5). Bridging the maker-user gap: The case of the Italian short film Acquario [Paper presentation]. Understanding Media Accessibility Quality (UMAQ) Conference, Barcelona, Spain.

Greco, G. M. (2018). The case for accessibility studies. Journal of Audiovisual Translation, 1(1), 205232. https://doi.org/10.47476/jat.v1i1.51

Remael, A., Orero, P., Black, S., \& Jankowska, A. (2019). From translators to accessibility managers: How did we get there and how do we train them? In M. Tolosa Igualada \& Á. Echeverri (Eds.), Porque algo tiene que cambiar: La formación de traductores e intérpretes, presente y futuro / Because something should change: Present and future training of translators and interpreters. MonTI, 11. https://rua.ua.es/dspace/bitstream/10045/99831/1/MonTI 1101 en.pdf

\author{
Aline Remael \\ University of Antwerp \\ aline.remael@uantwerpen.be
}

